\title{
RNA BASED THERAPIES - A POSITIVE OUTCOME OF COVID-19
}

Dear Reader,

It was way back in December 2014 that Ella Watson-Stryker was named TIMES Person of the Year for 2014 and featured on the Cover of Time Magazine. Dr Watson-Stryker was recognised with the honour, which she shared with all the healthcare workers who, undertrying circumstances, helped people in various west African countries fight the Ebola virus. While many experts predicted that the Ebola virus might cause a pandemic like situation across the world, the efforts of the healthcare workers ensured that Ebola virus was contained. However, the COVID-19 pandemic nearly five years

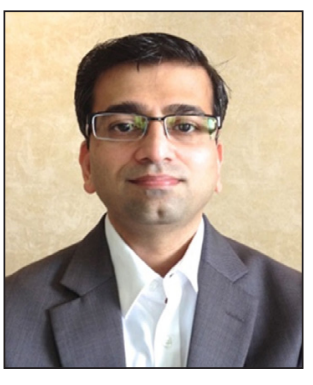
later created a similar desperate situation not just in a small region of the world but all across the globe. This desperate situation however, has facilitated the rapid development and acceptance of a new class of therapeutics called RNA based therapies.

The 2006 Nobel Prize in Physiology and Medicine was awarded to Andrew Fire and Craig Mello for discovering RNA interference (RNAi). Alnylam Therapeutics won the first approval for a RNAi based drug in 2018. However, the COVID-19 pandemic has helped RNA based technology to evolve rapidly. Two companies Moderna Therapeutics and BioNTech gained approvals from the FDA in the US and exponentially increased their revenues to billions of dollars over the past two years by commercializing RNA based vaccines for COVID-19. Today an entire new class of drugs based on RNA technology, targeting various diseases is expected to come to the market at a much more rapid pace as a result of the acceptance of the RNA based vaccines. The earlier issues associated with the delivery of these RNA based therapeutics have been resolved and the successful delivery to the targeted site has been demonstrated with the use of Lipid carriers. India's first mRNA based vaccine by Gennova Biopharmaceuticals is currently undergoing Phase II and Phase III clinical trials. We look forward to the successful indigenous development of this new class of vaccine and eventually the development of a new class of drugs in India for the treatment of various diseases. This will put India on a faster trajectory of establishing itself not only as a formidable supplier of generic drugs but also as an innovation hub for drug discovery.

As we move into this mode of innovation and develop new therapies, it is important that we improve the quality and scientific rigor used in our research methodologies. This calendar year, we wish to thank all our Reviewers, Editorial Board Members and Editorial Advisory Board Members who have spent their valuable time reviewing the large number of manuscripts that we received. We are grateful to them for their dedication and commitment to improve the research temperament of the manuscripts published in INDIAN DRUGS. An analysis of the manuscripts reviewed, indicates that only $25 \%$ of the manuscripts submitted are accepted for publication after an extensive peer review process by our editorial team.

It is observed that when we provide feedback to the authors of the various manuscripts, some authors take the comments of our reviewers positively and revise the manuscript promptly and diligently, improving the quality of their manuscripts. On the other hand, many authors defend their manuscripts and find fault with the reviewers and insist on the acceptance of a poorly presented or designed research output. 
In research conducted and published in the Journal Neuron(Bhanji, J. P. et al., Neuron. 2014 September 17; 83(6): 1369-1375), it was noted that on receiving a failing grade, while one student vows to do better, the other gives up. The student resolves to do better if failure was attributable to controllable factors i.e. he had studied differently, however a student gives up if failure was due to uncontrollable factors i.e.the professor was biased or the questions were unfair. Hence, our editorial team always suggest improvements that will help to improve the manuscript and facilitate acceptance. We look forward to increasing the acceptance rate of the manuscripts received, and hope the authors of the various manuscripts submitted to INDIAN DRUGS take control and address these suggestions positively resulting in greater acceptance ratios of all the manuscripts received.

Happy Reading and Wishing all a Happy New Year.

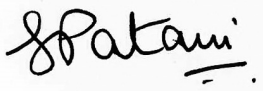

Dr. George Patani

Associate Editor

Indian Drugs

https://doi.org/10.53879/id.58.12.p0005

\begin{abstract}
9 About The Associate Editor

Dr George Patani, is a Pharmacist from the College of Pharmaceutical Sciences, Manipal. He completed his Masters in Medicinal Chemistry and Ph.D. in Drug Delivery from the Rutgers, The State University of New Jersey. He has approx. 22 years' experience at the INGA group of companies (namely Inga Laboratories P. Ltd and Inga Pharmaceuticals), developing and manufacturing phytochemical APIs and finished dose formulations. This experience has included an extensive record of project leadership in pharmaceutical formulation development and regulatory affairs. He has authored a number of scientific publications and book chapters with over a 1000+ citations from individual manuscripts.

Dr Patani is currently the Vice-President (Western Region) of the Indian Drug Manufacturers' Association 2022-till date. He was previously the Hon. Gen Secretary 2020-2021, Hon. Treasurer of IDMA 2017-2019, Chairman of IDMA's publication committee since 2012 and Chairman of IDMA's Industry Institute Interaction Committee from 2014 to 2019. He has been a recipient of the Outstanding Alumnus Award 2016 and Distinguished Alumnus Award 2005 from Manipal University. He has served on various committees such as the Crude Drugs and Herbal Products Committee of the Indian Pharmacopoeial Commission and the Reach Monitoring Committee of the TIFAC CORE in genomics at Manipal Academy of Higher Education etc.

म
\end{abstract}

If you would like to comment on the editorial please write to us at publications@idmaindia.com 